\title{
Telehealth language assessments using consumer grade equipment in rural and urban settings: Feasible, reliable and well tolerated
}

Rebecca Sutherland, BSPath (Hons), MHthSc (Developmental Disability)1,2,

David Trembath, BAppSc (Speech Pathology), MaAppSc (Communication Sciences and Disorders), $\mathrm{PhD}$,

Antoinette Hodge, BA (Psychology Hons), DPsy, MClin Neuropsych2,

Suzi Drevensek, BSc (Psychology), BAppSc (Speech Pathology Hons)2,

Sabrena Lee, BSPth (Hons)2,

Natalie Silove, MBBS, FRACP2

Jacqueline Roberts, BA (Hons), DipTeach, BAppSc (Speech Pathology), PhD1

1 Autism Centre of Excellence, Griffith University, Australia

${ }_{2}$ NSW Centre for Effective Reading \& Child Development Unit, The

Children's Hospital at Westmead, Australia

3Menzies Health Institute Queensland, Australia

Corresponding author:

Rebecca Sutherland, Child Development Unit, The Children's Hospital at

Westmead, Locked Bag 4001, Westmead NSW 2145, Australia.

Email: rebecca.sutherland@health.nsw.gov.au 


\section{Abstract}

Introduction: Telehealth can be an effective way to provide speech pathology intervention to children with speech and language impairments. However, the provision of reliable and feasible standardised language assessments via telehealth to establish children's need for intervention and to monitor progress has not yet been well established. Further, there is limited information about children's reactions to telehealth. This study aimed to examine the reliability and feasibility of conducting standardised language assessment with school-aged children with known or suspected language impairment via a telehealth application using consumer grade computer equipment within a public school setting.

Method: Twenty-three children (aged $8-12$ years) participated. Each child was assessed using a standardised language assessment comprising 6 subtests. Two subtests were administered by a speech pathologist face-to-face (local clinician) and 4 subtests were administered via telehealth. All subtests were completed within a single visit to the clinic service, with a break between the face to face and telehealth sessions. The face-to-face clinician completed behaviour observation checklists in the telehealth and face to face conditions and provided feedback on the audio and video quality of the application from the child's point of view. Parent feedback about their child's experience was elicited via survey.

Results: There was strong inter-rater reliability in the telehealth and face-to-face conditions (correlation coefficients ranged from $r=0.96-1.0$ across the subtests) and good agreement on all measures. Similar levels of attention, distractibility, and anxiety were observed in the two conditions. Clinicians rated only one session of 23 as having poor audio quality and no sessions were rated as having poor visual quality. Parent and child reactions to the use of telehealth were largely positive and supportive of using telehealth to assess rural children.

Discussion: The findings support the use of telehealth in the language assessment of school aged children using a web application and commercially available computer equipment. This reliable and 
innovative service delivery model has the potential to be used by speech pathologists to provide assessments to children in remote communities.

\section{Introduction}

Australia is a vast country with a relatively small population of approximately 24 million people ${ }^{1}$ concentrated in urban areas, with limited health, education and other services in rural areas ${ }^{2}$. A recent senate inquiry into speech pathology services in Australia ${ }^{3}$ found evidence of a shortage of speech pathologists, particularly outside urban areas, and that the ratio of speech pathologists to population falls as population density declines, from 25.9 per 100000 of population in major cities to 5.9 per 100000 of population in very remote areas. As a result, people in rural and remote areas experience significant barriers to accessing services ${ }^{4}$. The lack of services creates a significant risk for poor social and educational outcomes for those with language impairments living in rural and remote areas of Australia.

\section{Telehealth in Speech-Language Pathology}

Telehealth may overcome some of the difficulties associated with providing accessible speech pathology services and has been used successfully to treat a range of conditions including adult speech and language disorders ${ }^{5}$, dysphagia ${ }^{6,7}$, childhood fluency ${ }^{8}$, and speech sound disorders ${ }^{9}$.

Yet despite evidence for its utility in delivering interventions, only a small number of studies have examined the role for telehealth in standardised language assessment. Language assessments are crucial in establishing diagnoses, guiding intervention, and documenting progress in children with language difficulties.

The use of telehealth in the delivery of standardised language assessments has been examined in two studies ${ }^{10,11}$ (Eriks-Brophy et al. and Waite et al.) using method comparison designs, while the use of a langauge screening tool was evaluated in a further study ${ }^{12}$ (Ciccia et al.). In all three studies, the 
authors reported good reliability between face to face and online scoring of participant responses. Waite et al. ${ }^{11}$ trialled the use of the Clinical Evaluation of Language Fundamentals $-4^{\text {th }}$ edition (CELF-4) using a custom built internet-based telehealth application with store and forward capabilities and touch screen at the participant's end. The picture stimuli were digitised. An audio recording of the stimulus for one subtest assessment was used, along with live presentation of the remaining 3 subtest materials. As with EriksBrophy $^{10}$ and Ciccia et al. ${ }^{12}$, a method comparison design ${ }^{13}$ was utilised with simultaneous scoring by a face to face and online assessor, in this case between two assessment rooms in a university clinic. Students and clinicians were randomised to face to face or online conditions. Very good levels of interand intra- rater agreement were found on all measures with some variation between subtests $(\mathrm{K}=.93$ >.99). A limitation of this study, as noted by Taylor et al. ${ }^{13}$, is that it was not conducted in a real-world setting but rather under ideal research conditions. In addition, none of the studies reported client or clinician satisfaction and only Ciccia et al. reported on parent satisfaction. Finally, the studies did not include comparisons of child behaviour across face to face and online conditions.

The data to date regarding telehealth assessment is promising, however the current lack of information about the reliability and feasibility of conducting telehealth assessments in routine clinical settings with commercially available equipment, as well as parent, child, and clinician responses to the approach, represents a significant gap in the literature. Research is needed to examine the effectiveness of telehealth language assessment in the context of existing service delivery models, as well as to begin to address identified barriers to speech pathologists using telehealth. These include beliefs that parents hold negative attitudes towards its use ${ }^{14}$, and that telehealth can only be used in specialised research or university settings, rather than real world clinical services ${ }^{15}$. Other concerns held by speech pathologists who do not use telehealth include fear of technology and concerns regarding their ability to develop rapport with remote clients (15) 
The aims of this study were to determine whether within an existing service, a web-based telehealth application using consumer grade, commercially available computer equipment could be used to provide a formal language assessment that is feasible, reliable and well tolerated by participants and their families. In this study, children were in the same location as a second speech pathologist (face-toface speech pathologist) whose role was to facilitate the assessment, replicating a real-world setting in which children could be supported by teachers or other school support staff during assessment. It was hypothesised that under these conditions, standardised language assessment delivered via telehealth would be feasible, reliable and well tolerated by participants and their families.

\section{Method}

Ethics approval was received from the Sydney Children's Hospital Network (SCHN) Human Research Ethics Committee (HREC Reference: LNR/12/SCHN/408). Approval was also obtained from the NSW Department of Education. Written consent was obtained from parents and children were provided with an illustrated Social Story® to support their understanding of the project.

\section{Design}

A method comparison design was used ${ }^{16}$ in order to measure the agreement between the scores for each language assessment subtest recorded by the telehealth speech pathologist compared with those made simultaneously by the face-to-face speech pathologist. This method allows researchers to quantify the variation between two methods of measurement for the same subject. The independent variable was the condition under which the assessment was conducted (telehealth vs face to face). The dependent variables were: a) number of scheduled sessions that were completed successfully (DV1) and face-to-face speech pathologists ratings of audio and visual quality (DV2) which provided measures of feasibility; b) the language assessment scores given by the telehealth and face to face speech pathologists which were compared to provide a measure of reliability (DV3), and; c) behaviour 
observation scores made by the face to face speech pathologist in the face to face and telehealth conditions, providing a measure regarding the behaviour of the children and how well the telehealth condition was tolerated (DV4), along with parent survey information (DV 5).

\section{Participants}

Participants were 23 children ( 18 male, 5 female) aged $8-12$ years (mean $=9$ years, 11 months) with a history of reading difficulties and known/suspected language impairment, attending mainstream schools. They were referred to a specialist reading centre, a service for children with reading difficulties who live in rural and remote NSW, Australia. Children were referred by their schools based on their poor response to reading interventions and attended one of two rural 'hubs' in or a suburban hub for multidisciplinary assessment, including a thorough language assessment. The participating students were a sample of convenience, based on those students attending the service. There were no exclusionary criteria; however, children did not participate if they had had a language assessment using the CELF-4 within the previous six months.

Three experienced (mean=13.7 years of work experience, range 10-19 years) local speech pathologists consented to participate in the project (i.e., co-scoring and delivering assessments) as part of their regular work with (Name withheld for review). They were all experienced in administering the paper form of the CELF-4 and regularly used technology for communication in the workplace (e.g. videoconferencing with colleagues). Two of the three speech pathologists reported having limited experience in delivering speech and/or language intervention via computer (e.g. using Adobe Connect). None had used the current telehealth interface prior to the project. The telehealth speech pathologist had four years clinical experience and was familiar with the language assessment tool. She reported familiarity with a range of technology applications (e.g. Skype, computer use) but had less experience 
using technology for communication in the workplace (e.g. videoconferencing) and no experience of telehealth prior to the project.

\section{Materials}

Assessment tool

The CELF $-4{ }^{17}$ is a standardised, individually administered clinical tool for the identification, diagnosis, and follow-up evaluation of language skill deficits in school-age children, adolescents, and young adults. Permission was granted by Pearson Australia to digitise images of the CELF-4 for use in online administration. The test images were scanned and converted to JPEG files which were then uploaded to the application. The published psychometric properties of the CELF-4 include stability coefficients ranging from 0.77 to 0.94 , internal consistency for the Core Language Score (a composite score indicating the presence or absence of a language impairment along with the severity of the impairment) ranging from 0.97 across age ranges ${ }^{17}$. The Core Language Score is based on four core subtests. For the $5-8$ age group these are Concepts and Following Directions, Word Structure, Recalling Sentences and Formulated Sentences. Students aged $9-12$ complete also 3 of these subtests (Concepts and Following Directions, Recalling Sentences and Formulated Sentences) as well as Word Classes which yields an expressive and a receptive score. Inter scorer reliabilities are described as .99 or 1.0 across all CELF-4 Australian subtests. The core subtests for $9-12$ year olds include two subtests that require the administrator to score a response as correct/incorrect (Concepts and Following Directions; Word Classes - receptive). Two subtests require the administering clinician to make a subjective judgement with reference to scoring guidelines to score a response as correct or incorrect (Word Classes - expressive) or to score 0,1 or 2 based on the number of grammatical and/or syntactical errors made by the child (Formulated Sentences). The final subtest (Recalling Sentences) can be scored as $0,1,2$ or 3 based on the number of errors made during immediate repetition of a spoken sentence. While scoring for this subtest is not subjective, the reliability of scoring is dependent on precise notation of 
the child's response. All participants completed the four core subtests via the telehealth application. Two additional subtests were administered by the face-to-face speech pathologist, along with any other clinically relevant assessments required.

\section{Equipment}

The assessment was delivered via a telehealth application developed by National Information Communication Technology Australia (NICTA). This web-based interface included synchronised image viewing and remotely visible click-markers for pointing at images as well as video conference functionality. The computers used were standard issue Department of Education devices with consumer grade webcams (Logitech C920) and speakers (Logitech PC Z130). A commercially available touch screen from Dell (model S2240T) was supplied to the local sites. All four sites (telehealth setting and the three hubs) were located within NSW Department of Education public schools and used the internet connection available to these sites. The application was designed to allow a speech pathologist using telehealth to complete the assessment with the child supported by a school staff member (teacher or teacher aide) in their local setting. For the purpose of this research, a speech pathologist acted as a support person to facilitate assessments (rather than a teacher or teacher aide) in order to co-score the assessment tasks delivered by the telehealth speech. This allowed for the comparison of scores for the study without adding extra team members to the assessment environment.

\section{Procedure}

Training

The telehealth speech pathologist was trained in the use of the interface by the developer and a senior speech pathologist (RS) in a single session. The face-to-face speech pathologists were shown the interface in a group setting and subsequently given information and an opportunity to practice using the application in a session with the telehealth speech pathologist. This information session provided details 
on how to log into the application, camera positioning, room set up, and general troubleshooting. Training for both the telehealth and face-to-face speech pathologists took less than 30 minutes.

A group session was held with all speech pathologists, as well as other senior speech pathologists employed by the service, to practice scoring the subjective subtests in accordance with the CELF-4 manual instructions. This provided the telehealth and face-to-face speech pathologists with an opportunity to review standard scoring guidelines and to participate in a practical component where the clinicians practiced scoring a series of sample sentences. Reliability was not formally established, however consensus was reached for each example in accordance with the CELF-4 scoring guidelines. All assessments were carried out as per the CELF-4 manual.

\section{Assessment procedure}

The assessments were conducted from the metropolitan telehealth site in Westmead, NSW, to the three hub sites in rural NSW (Hub 1 and Hub 3) and suburban Sydney, NSW (Hub 2). The telehealth speech pathologist administered the four core subtests of the CELF-4 via the telehealth application and scored the children's responses (approximately $45-60$ minutes). The face-to-face speech pathologist was with the child during the telehealth assessment and facilitated the assessment by turning on the computer, logging into the application and checking vision and sound. She then co-scored the assessment as an observer. The face-to-face speech pathologist also completed two non-core CELF-4 subtests and other language assessments (as clinically indicated) with the student face to face (approximately $30-60$ minutes depending on clinical need). These face to face assessments were completed either before or after the telehealth session depending on the scheduling demands of the hub, resulting in non-randomised counter-balanced delivery order (17/23 completed face to face assessment tasks first). . All subtests were completed within a single visit to the clinic service, with a break between the face to face and telehealth sessions. The face-to-face speech pathologist completed behaviour 
observations of the children in both face to face and telehealth conditions in order to provide feedback about the child's behaviour that may not have been able to be seen.

\section{Measures}

Measures of feasibility (DV1, DV2)

The telehealth speech pathologist kept records regarding the number of scheduled sessions completed and reported any issues resulting in non-completion of the assessment due to child, clinician, or technological factors (DV1). The telehealth and face-to-face speech pathologists both recorded observations regarding the technology during each session, noting the audio and video quality on a three point scale (poor, OK, good) (DV2).

\section{Measures of reliability (DV3)}

Measures of reliability involved both the telehealth and face-to-face speech pathologists simultaneously scoring the core subtests of the CELF-4. These measures were collected and scored as per the standard administration instructions for the CELF-4. Core Language Scores were calculated and severity rankings of language impairment were assigned as per administration guidelines. Method comparison analysis and Pearson's correlation were used to determine level of agreement and reliability.

\section{Measures of behaviour (DV4)}

A behaviour observation rating scale was adapted from the Clinical Evaluation of Language Fundamentals - Preschool $2^{\text {nd }}$ edition, Australian and New Zealand (CELF-P2) behaviour checklist. No such checklist accompanies the CELF-4 but the CELF-P2 checklist contained relevant items for this population. Observations about anxiety and the types of distractors (test equipment and non-test items) were added to those describing activity and interaction levels, attention to task and distractibility. The rating scale is presented in Table 1. 
Measures of parent satisfaction (DV5)

Parents completed a simple survey following the telehealth assessment that asked 'Do you think your child felt comfortable during the (telehealth) assessment?' and 'Did you feel comfortable during the (telehealth) assessment' with four options: 'yes definitely', 'yes, somewhat', 'no' and 'don't remember'. The survey was completed and returned anonymously to the research team.

\section{Results}

Feasibility

One hundred percent (23 of 23) assessment sessions were completed; no sessions were discontinued due to technological or other difficulties. Ratings of audio and visual quality ('poor', - 'good') were converted to numerical scores $(0,1,2)$. Audio was rated as 'good' in $74 \%$ of sessions, and inconsistent or 'OK' in a further $22 \%$. Only one session was rated as 'poor'. The average audio rating for hub 1 was $1.88($ mode $=2$, range $1-2)$, for hub 2 it was $1.43($ mode $=2$, range $0-2)$ and for hub 31.75 (mode $=2$, range $1-2$ ). Audio problems occurred more frequently in one Hub; these were mostly related to low volume and words occasionally cutting out. It is unclear whether this was related to high demands on bandwidth in that setting or if other factors caused these difficulties. Visual quality was rated as 'good' in $83 \%$ of sessions. No sessions were rated as 'poor'. The average visual quality rating for hub 1 was $1.88(\operatorname{mode}=2$, range $1-2)$, for hub 2 was $1.71(\operatorname{mode}=2$, range $1-2)$ and for hub $3,1.88($ mode $=2$, range $1-2)$.

\section{Reliability}

Bland-Altman analyses were used to assess the level of agreement for the Core Language Score and the raw scores of the four core subtests by plotting the mean (x-axis) versus the difference ( $y$-axis) between the two measures (telehealth and face to face) (Figures 1). In these analyses, zero equals 
perfect agreement and the larger the number for each plot point, the greater the disagreement between assessors. Calculations of $95 \%$ limits of agreement for each comparison (average difference \pm 1.96 standard deviation of the difference) were made for each subtest. Plots showed no clear trend in difference between the assessors, and the variance did not appear to differ with the mean. Furthermore, evidence of strong correlations was found between conditions for all measures ranging from $0.96-1.0$ as shown in Table 2. There was complete agreement on severity level for 22 of the 23 children (96\%) with one student's rating only differing by one severity level.

\section{Behaviour}

Behaviour, as measured by the behaviour observation checklist, was analysed using paired ttests. Initial analysis of the data indicated differences between the hubs, with one hub showing greater variability between the face to face and telehealth speech pathologists. Behaviour data was subsequently analysed in three groups, according to the location of the child. The two rural hubs showed no difference in observed behaviour between the conditions. In contrast, the suburban hub showed greater levels of behaviour difficulty in the telehealth condition for some students, however this difference did not reach significance at .05 (see Table 3).

\section{Parent Satisfaction}

Thirteen parents of the 23 participants returned the survey anonymously (56\%). All parents described their child and themselves as being 'somewhat comfortable' or 'definitely comfortable' with the telehealth assessment. Table 4 presents parents' comments regarding their experience. No parents indicated that they felt uncomfortable with the assessment. Many of the comments from parents indicated that their child had found the experience positive and a number reflected positively on their own experience or opinion of the telehealth assessments. Two parents expressed concern: one parent felt 
their child lost concentration when he got a question wrong; the second parent stated their child "did like to use the computer and the videoconferencing .... but he would prefer to talk to a person face to face".

\section{Discussion}

This study aimed to examine the reliability and feasibility of conducting standardised language assessment with school-aged children with known or suspected language impairment via a telehealth application using consumer grade computer equipment within a public school setting. The feedback from all the speech pathologists involved suggested that the system used was feasible, with the telehealth speech pathologist able to complete all assessments with good levels of audio and visual quality. Given that the system is designed for speech pathologists to deliver assessments online within schools, and for children to be supported in the assessment session by teachers or teaching assistants (rather than local speech pathologists), the feasibility of the system and the ability to assess children reliably was of particular interest.

In terms of reliability, a high level of agreement was reached between the telehealth and face-toface speech pathologists on all subtest raw scores, scaled scores, and core language scores, indicating that the responses received and recorded by the telehealth speech pathologist were very similar to those recorded by the face to face speech pathologist. These results are in line with those reported by Waite and colleagues ${ }^{11}$ in their study of $5-9$ year olds whose language was assessed using the CELF-4 via telehealth. Their study found very good agreement between telehealth and face to face scorers when assessing children using custom built equipment in a university setting, with some variation between subtests $(\mathrm{k}=.93->.99)$. The present study adds to their findings by completing the assessments in real time and remote locations with consumer grade, commercially available equipment that is readily available in the community and user friendly. The telehealth clinician was able to learn to use the system easily and the face-to-face speech pathologists supporting the child required minimal training. It is 
anticipated that education staff in regional schools will be able to provide appropriate support for telehealth assessments in the future.

The behaviour of individual children under telehealth conditions and their reaction in comparison to typical face to face sessions has not been systematically examined in research published to date. This study found few differences in the clinician-reported child interaction, attention or anxiety levels across the two conditions when analysed in separate hubs. Differences were observed, however, between the hubs, with one clinician reporting that the children showed more behaviour difficulties when engaged in the telehealth assessments, although the differences between conditions did not reach significance. This hub also experienced more audio and visual difficulties than the other two hubs and it is possible that these difficulties impacted on some students' attention and engagement. In addition the effect of different interaction styles between the hub therapists cannot be ruled out. It will be important for children involved in telehealth assessments to be supported to ensure that they are able to attend and interact appropriately.

The present study found good levels of parent satisfaction with the technology, in line with the findings of Ciccia et al. ${ }^{12}$ who found high levels of parent satisfaction with speech and language screening conducted via Skype, and a preference for parents to access this service compared to attending separate speech and language assessments. Similarly, Dunkley and colleagues ${ }^{14}$ found that rural residents expressed willingness to trial services provided in this way, in part because of their isolation and lack of alternative services. The results of the current study indicated positive attitudes towards the use of telehealth in this setting with all families indicating that both they and their children felt comfortable using the telehealth system. 
The barriers to using telehealth described by a number of authors have been somewhat addressed in this study ${ }^{15,18}$. The study attempted to mitigate financial and access barriers by conducting assessment in local schools, using commercially available equipment with standard school based computer equipment and internet access. While proportionately fewer rural and remote homes have internet access compared to homes in urban areas ${ }^{19}$, schools generally have access even in very remote areas and all government schools in NSW, for example, have been connected to the internet since $1996^{20}$. Barriers arising from technology difficulties were addressed using a simple to access, web-based application that required no download or installation and no technical knowledge beyond accessing a web page. Cultural barriers, including reluctance to engage in telehealth and the belief that telehealth is restricted to research settings were addressed in this study by showing that the use of telehealth in a realworld setting, outside a specialist research facility ${ }^{15}$ is feasible. The effectiveness of using telehealth in a clinical setting was reflected in the good reliability of scores across conditions, in high parent satisfaction ratings, and in how well the telehealth assessments were tolerated by the children, as demonstrated by the behaviour observations across conditions.

\section{Limitations}

The present study contains a number of limitations. As with Waite and colleagues ${ }^{11}$, only the four core language subtests were administered rather than all the subtests required for a comprehensive assessment. Additionally, only moderate numbers $(n=23)$ were involved in this cohort and no comparison group was included. While some counterbalancing to control for order effects occurred naturally, this was not randomised. However, in keeping with the real-world clinical caseloads, no children were excluded from the assessment. All those who could be assessed by both the telehealth and face-to-face speech pathologists during the study timeframe were included, with no refusals or withdrawals from the study.

\section{Future research}


The findings of the present study support the use of a telehealth application to assess the language of children with reading difficulties in a real-world situation using commercially available equipment. Future studies should investigate the feasibility and tolerability of telehealth assessments of children with diverse learning needs, including those with additional social and behavioural difficulties that may impact on assessment administration (e.g., children with autism spectrum disorder). The use of telehealth to undertake all subtests of formal assessment, along with other language measures such as narrative assessments and conversation should also be considered. Finally, it will be important to examine the practicalities of using of telehealth systems for language assessments in clinic and education settings with the support of educators or teaching assistants to manage the assessments.

\section{Acknowledgements}

The authors wish to acknowledge: Silvia Pfeiffer, Terence Percival and Rosemary Hollowell of National ICT Australia (NICTA); Marcia Williamsz, Kate Baggett, Fiona Eastley, Chantelle Medley, Sylvia Pope, Jenny Rayner and Neale Waddy of The NSW Centre for Effective Reading, NSW Department of Education; and The Child Development Unit, The Children's Hospital at Westmead.

\section{Declaration of Conflicting Interests}

The Authors declare that there is no conflict of interest.

\section{Funding}

The author(s) disclosed receipt of the following financial support for the research, authorship, and/or publication of this article: this work was supported by the NSW Department of Education. National ICT Australia provided in-kind support in the form of the design of the assessment website interface.

\section{References}


1. Australia Bureau of Statistics. Australia demographic statistics (cat. no. 3101.0). Canberra, ACT: ABS, 2014..

2. Australian Institute of Health and Welfare. Health and community services labour force. National health labour force series number 42. Cat. no. HWL 43. Canberra, ACT: AlHW, 2009.

3. Community Affairs References Committee. Prevalence of different types of speech, language and communication disorders and speech pathology services in Australia. Canberra, ACT: Community Affairs References Committee, 2014.

4. O'Callaghan AM, McAllister $L$ and Wilson $L$. Barriers to accessing rural paediatric speech pathology services: health care consumers' perspectives. Australian Journal of Rural Health. 2005; 13: 162-71.

5. Constantinescu G, Theodoros D, Russell T, Ward E, Wilson S and Wootton R. Assessing disordered speech and voice in Parkinson's disease: a telerehabilitation application. International Journal of language and Communication Disorders. 2010; 45: 630 - 44.

6. Sharma S, Ward EC, Burns C, Theodoros D and Russell T. Assessing dysphagia via telerehabilitation: patient perceptions and satisfaction. International Journal Of Speech-Language Pathology. 2013; 15: 176-83.

7. Ward EC, Sharma S, Burns C, Theodoros D and Russell T. Validity of conducting clinical dysphagia assessments for patients with normal to mild cognitive impairment via telerehabilitation. Dysphagia. 2012; 27: 460-72.

8. Lewis C, Packman A, Onslow M, Simpson JM and Jones M. A phase II trial of telehealth delivery of the Lidcombe Program of Early Stuttering Intervention. American Journal of Speech-Language Pathology. 2008; 17: 139-49.

9. Grogan-Johnson S, Schmidt AM, Schenker J, Alvares R, Rowan LE and Taylor J. A Comparison of Speech Sound Intervention Delivered by Telepractice and Side-by-Side Service Delivery Models. Communication Disorders Quarterly. 2013; 34: 210-20.

10. Eriks-Brophy A, Quittenbaum J, Anderson D and Nelson T. Part of the problem or part of the solution? Communication assessments of Aboriginal children residing in remote communities using videoconferencing. Clinical Linguistics \& Phonetics. 2008; 22: 589-609.

11. Waite MC, Theodoros DG, Russell TG and Cahill LM. Internet-Based Telehealth Assessment of Language Using the CELF-4. Language, Speech, and Hearing Services in Schools. 2010; 41: 445-58.

12. Ciccia AH, Whitford B, Krumm M and McNeal K. Improving the access of young urban children to speech, language and hearing screening via telehealth. Journal of Telemedicine and Telecare. 2011; 17: 240-4.

13. Taylor OD, Armfield NR, Dodrill P and Smith AC. A review of the efficacy and effectiveness of using telehealth for paediatric speech and language assessment. Journal Of Telemedicine And Telecare. 2014; 20: 405-12. 
14. Dunkley C, Pattie L, Wilson L and McAllister L. A comparison of rural speech-language pathologists' and residents' access to and attitudes towards the use of technology for speech-language pathology service delivery. International Journal of Speech-Language Pathology. 2010; 12: 333-43.

15. May J and Erikson S. Telehealth: Why not? Perspectives of speech pathologists not engaging in telehealth. Journal of Clinical Practice in Speech-Language Pathology. 2014; 16: 147 - 51.

16. Bland JM and Altman DG. Measuring agreement in method comparison studies. Statistical methods in medical research. 1999; 8: 135-60.

17. Semel E, Wiig E and Secord W. Clinical Evaluation of Language Fundamentals, 4th edition. San Antonio, TX: Harcourt Assessment, Psychological Corporation., 2003.

18. Jang-Jaccard J, Nepal S, Alem L and Li J. Barriers for delivering telehealth in rural Australia: a review based on Australian trials and studies. Telemedicine Journal and e-Health. 2014; 20: 496-504.

19. Australia Bureau of Statistics. Online @ Home, Australian Social Trends, cat. no. 4102.0. Canberra, ACT: ABS, 2011.

20. Standing Council on School Education and Early Childhood. National Report on Schooling in Australia. Melbourne, Australia: SCSEEC, 1996. 
Tables and figures

Table 1. Behaviour rating scale.

\begin{tabular}{|c|c|}
\hline The child was: & Compliant \\
\hline & compliant with support \\
\hline & Noncompliant \\
\hline The child's activity level was: & Appropriate \\
\hline & too active \\
\hline & not active enough \\
\hline The child was fidgety/restless: & Never \\
\hline & some of the time \\
\hline & most of the time \\
\hline The child required breaks: & Never \\
\hline & at appropriate times \\
\hline & too frequently (interfered with testing) \\
\hline The child maintained attention: & the whole time \\
\hline & most of the time \\
\hline & some of the time \\
\hline & Never \\
\hline The child was distracted by test-related factors or & Never \\
\hline 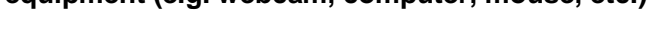 & occasionally \\
\hline & Often \\
\hline The child was distracted by non-test-related & never \\
\hline pictures on walls etc.): & occasionally \\
\hline & Often \\
\hline The child engaged in off-task behaviours: & never \\
\hline & occasionally \\
\hline & Often \\
\hline The child demonstrated fatigue, boredom and/or & never \\
\hline & Rarely \\
\hline & sometimes \\
\hline & Often \\
\hline Fatigue, boredom and/or frustration became & never \\
\hline & after $15 \mathrm{~min}$ \\
\hline & after $10 \mathrm{~min}$ \\
\hline & after $5 \mathrm{~min}$ \\
\hline The child demonstrated anxiety/nervousness & the whole time \\
\hline & most of the time \\
\hline & some of the time \\
\hline & never \\
\hline The child requested help, support or clarification: & never \\
\hline & occasionally \\
\hline & Often \\
\hline
\end{tabular}


Table 2. Correlation coefficients for the CELF-4 subtest raw scores.

\begin{tabular}{lccc}
\hline Test Scores & N & Correlation & p-value \\
\hline Subtest Scaled Scores & & & \\
Concepts \& Following Directions & 23 & 0.99 & $<0.001$ \\
Formulated Sentences & 23 & 0.97 & $<0.001$ \\
Word classes (receptive) & 19 & 1.0 & $<0.001$ \\
Word classes (expressive) & 19 & 0.96 & $<0.001$ \\
Recalling sentences & 23 & 0.96 & $<0.001$ \\
Core Language Score & 23 & 0.99 & $<0.001$ \\
\hline
\end{tabular}

Table 3. Paired Sample T-Test comparing telehealth and face to face behaviour ratings in each hub.

\begin{tabular}{|c|c|c|c|c|c|c|c|c|}
\hline & \multicolumn{5}{|c|}{ Paired Differences } & \multirow[t]{3}{*}{$\mathrm{t}$} & \multirow[t]{3}{*}{ df } & \multirow{3}{*}{$\begin{array}{l}\text { Sig. }(2- \\
\text { tailed })\end{array}$} \\
\hline & \multirow[t]{2}{*}{ Mean } & \multirow[t]{2}{*}{$\begin{array}{c}\text { Std. } \\
\text { Deviation }\end{array}$} & \multirow[t]{2}{*}{$\begin{array}{c}\text { Std. Error } \\
\text { Mean }\end{array}$} & \multicolumn{2}{|c|}{$\begin{array}{l}\text { 95\% Confidence Interval of the } \\
\text { Difference }\end{array}$} & & & \\
\hline & & & & Lower & Upper & & & \\
\hline Hub 1 & .37500 & .74402 & .26305 & -.24702 & .99702 & 1.426 & 7 & .197 \\
\hline Hub 2 & 2.71429 & 3.25137 & 1.22890 & -.29273 & 5.72130 & 2.209 & 6 & .069 \\
\hline Hub 3 & .87500 & 1.88509 & .66648 & -.70098 & 2.45098 & 1.313 & 7 & .231 \\
\hline
\end{tabular}

Table 4. Parent comments regarding satisfaction.

\begin{tabular}{|c|c|}
\hline Parent & Comment \\
\hline 1 & No issues at all \\
\hline 2 & Was very relaxed and enjoyable \\
\hline 4 & $\begin{array}{l}\text { I believe this is a great idea. This could expand to the bush; where services are in need. Keep up the } \\
\text { good work }\end{array}$ \\
\hline 5 & $\begin{array}{l}\text { My child thought (the telehealth speech pathologist) was very friendly. I thought she did very well at } \\
\text { making him feel comfortable and was very good at judging when he needed a break }\end{array}$ \\
\hline 7 & (Child) done (sic) very well, I was very happy \\
\hline 8 & $\begin{array}{l}\text { (My child), who was reluctant to attend the centre, stated after this videoconferencing assessment that } \\
\text { he "liked coming" and was "having fun". A statement never made before when in conjunction with } \\
\text { education and/or learning }\end{array}$ \\
\hline 9 & (My child) seemed excited and happy to be doing work on computer and video chat \\
\hline 10 & (My child) enjoyed himself and said it was fun \\
\hline 11 & $\begin{array}{l}\text { It showed us some of the areas where (my child) has difficulty. I felt the videoconference was very } \\
\text { worthwhile }\end{array}$ \\
\hline 12 & $\begin{array}{l}\text { I found when he got a question wrong he would loose (sic) concentration then would take another } 3 \text { to } \\
4 \text { questions to get back on track }\end{array}$ \\
\hline 13 & $\begin{array}{l}\text { (My child) did like to use the computer and the videoconferencing was quite a novelty for him but he } \\
\text { would prefer to talk to a person face to face without the computer link up. I also thought the sound } \\
\text { through the computer was difficult at times to hear/understand. (My child) spent a lot of time } \\
\text { concentrating on understanding what was being said }\end{array}$ \\
\hline
\end{tabular}


Figure 1. Bland Altman plots and scatterplots illustrating interrater agreement and reliability across subtests.
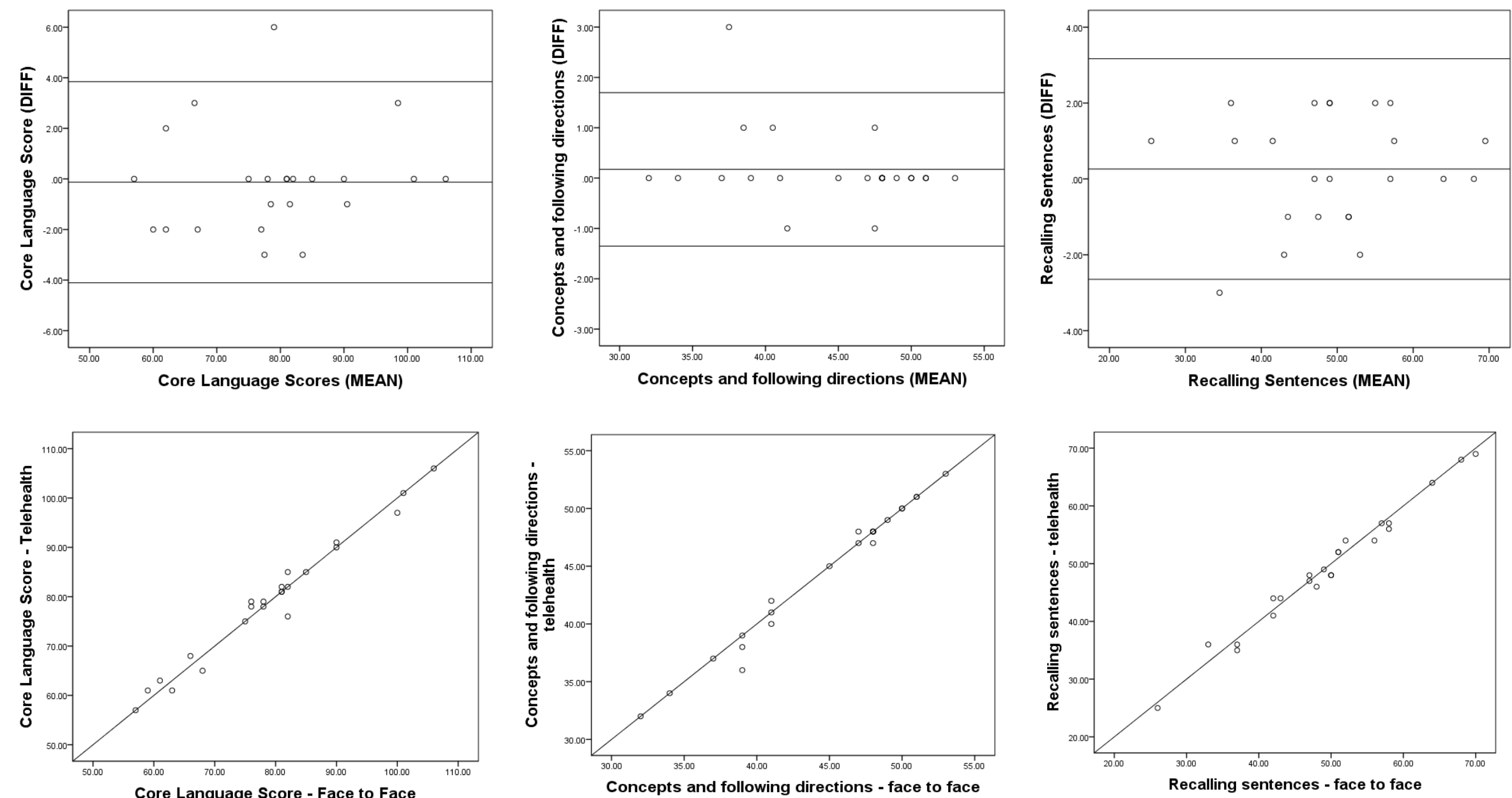

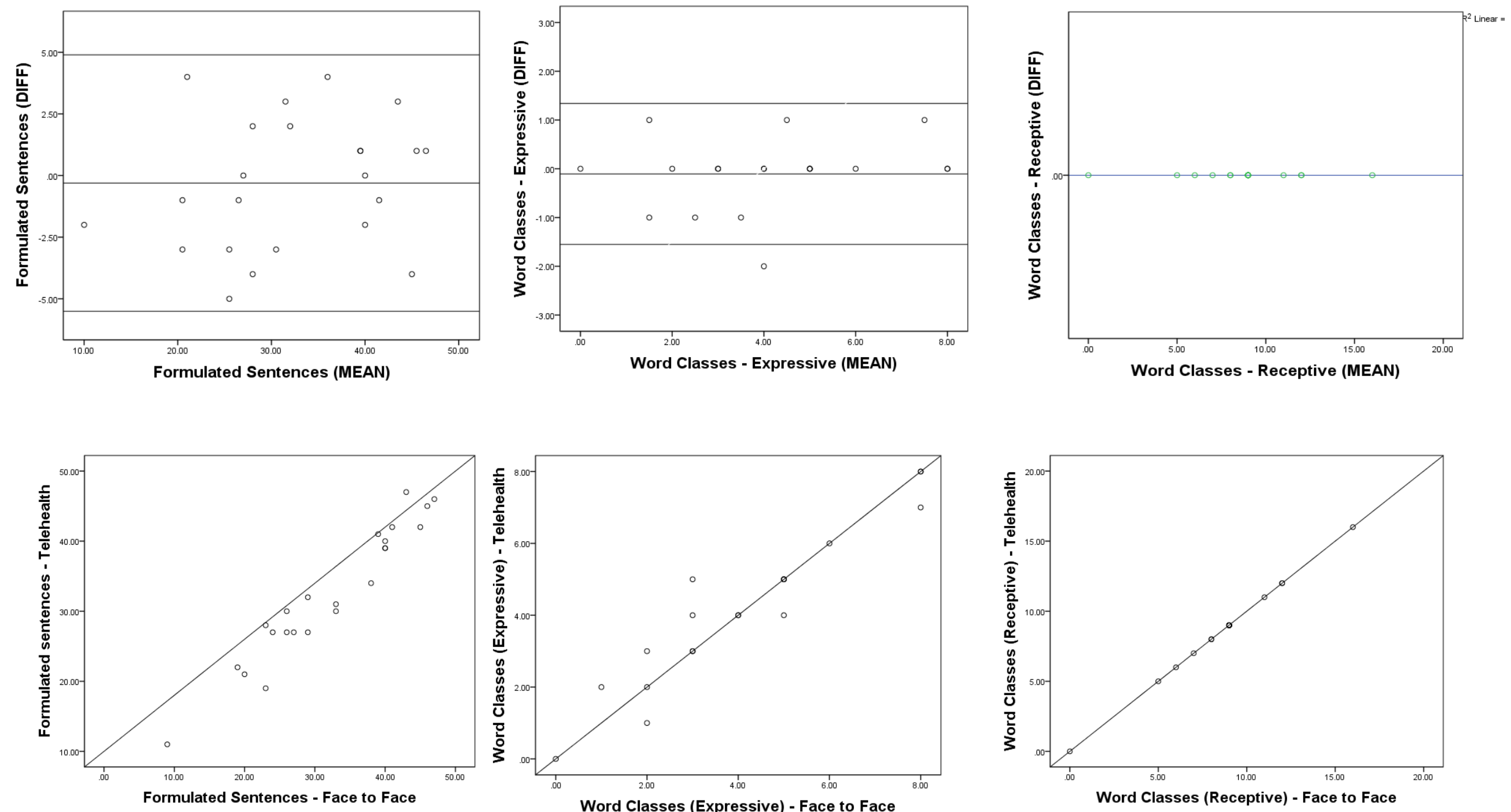

Word Classes (Receptive) - Face to Face 
